Kaipia, R., Holmström, J., Hellström, M. (2007), Measuring the benefit of changing the value offering in grocery supply chains, Production Planning \& Control, Vol. 18, Iss. 2, pp. 131-141.

(C) 2007 by authors and (C) 2007 Taylor \& Francis

Preprinted with permission.

This is a preprint of an article whose final and definitive form has been published in the Production Planning \& Control. Production Planning \& Control is available online at http://www.informaworld.com.

http://www.informaworld.com/openurl?genre=article\&issn=0953$7287 \&$ volume $=18 \&$ issue $=2 \&$ spage $=131$ 


\title{
MEASURING THE BENEFIT OF CHANGING THE VALUE OFFERING IN GROCERY SUPPLY CHAINS
}

\author{
Riikka Kaipia, Jan Holmström, Mikael Hellström \\ Helsinki University of Technology \\ BIT Research Centre \\ Published in Production Planning and Control, Vol. 18, No. 2, March 2007, pp. 131-141.
}

\begin{abstract}
New value-adding solutions are needed for grocery supply chains to gain a sustainable competitive advantage in a market environment characterized by increased competition. This paper discusses two case studies that identify how improvements to the value offering brought about enhancements to the performance of the total supply chain. The concept of time benefit analysis is applied to measure the impact of the change. These approaches offer novel and unique techniques for performance measurement and value offering analysis in supply chain management.
\end{abstract}

Keywords: supply chain, value offering theory, time benefit analysis, VMI, information change.

\section{Introduction}

This article presents how innovative connections between supply and demand can be systematically sought in order to improve operational performance. Suppliers are increasingly interested in how their customer companies are operating and how customer processes affect the supplier's operational efficiency. Suppliers are offering more services to their customers and thus moving away from transactional business settings. By offering value-adding services to its customers, the supplier becomes a co-producer of value together with the customer. This new role creates an opportunity to increase the supplier's own operational efficiency, while simultaneously providing better service to the customer. Thus, customer service is seen as an enabler of logistical efficiency. Combined with understanding the customer's situation, it also contributes to high customer satisfaction.

The value offering theory presented by Holmström et al. (1999) describes how demand and supply are connected and how supply and demand can be managed in different phases of the supply chain. This theory was developed by consultants at the McKinsey \& Company Supply Chain Practice, together with researchers from Helsinki University of Technology. It is proposed that by using and applying a specific representation model, companies can systematically analyse, from a supply chain perspective, what the value is that they are offering to their customers and how they can further develop their supply chain performance.

An other management tool, that has been developed by Kaipia et al. 2002, can be used to measure the impact of changing the value offering point (VOP). This tool is called time benefit method (TBM), and it provides information about how much the supply chain parties benefit, if they implement a change in their collaborative practices. For example, if a supplier can use the customer's demand information, the supplier gets more time to react to demand changes compared to a situation when it operates based on orders. The difference between available time for the supplier in these two situations can be calculated using TBM.

This article discusses the application and measurement of value offering analysis. The goal is to present how the value offering theory and time benefit method can be used in practice to develop supply chain operations. This is done in two case studies, one from a supplier-manufacturer interface 
and one from a manufacturer-reseller interface. Another goal is to analyse the differences in employing the tools in upstream and downstream operations.

In this article we introduce the principles of value offering methodology and the concept of time benefit; then, second, we discuss the applied methodology and draw inferences from two cases where the tools are further explored; finally, we discuss our key findings and the conclusions that can be drawn from our work.

\section{VOP theory: order penetration point and value offering point}

The demand chain transfers demand from markets to suppliers (Vollman et al., 1996); it consists of the activities that lead to a need of a product. For example, a demand chain would consist of sales, inventory management and purchasing. The supply is the process where value is created to fulfill the customer's need. Demand and supply in a customer-supplier relationship are connected via two links: the order penetration point (OPP) and value offering point (VOP), as shown in Figure 1 (Holmström et al., 1999). Compared to other value analysis tools, for example value stream mapping (see for example Wood, 2004 and Lovelle, 2001), this tool aims at understanding the interfaces and connections inside a supply chain. While value stream mapping aims at lean supply chains and eliminating waste, this tool concentrates on the value a supplier can offer to the customer.

The order penetration point is the stage in the supply chain from which onwards delivery is made to customer orders (Olhager, 1994). The OPP determines how and when a product is allocated to the customer (Sharman, 1984). Before the order penetration point, supply chain operations are based on forecasts, and after the OPP every product is dedicated to a specific customer. The OPP is also known in the literature as the customer order decoupling point, CODP, (Hoekstra and Romme, 1992), which is the point on the product axis where customer orders penetrate. Also the term DPP, demand penetration point, is used, meaning the point where real demand meets the plan (Christopher, 1998). DPP separates the operations based on forecasts (plan) and operations based on demand.

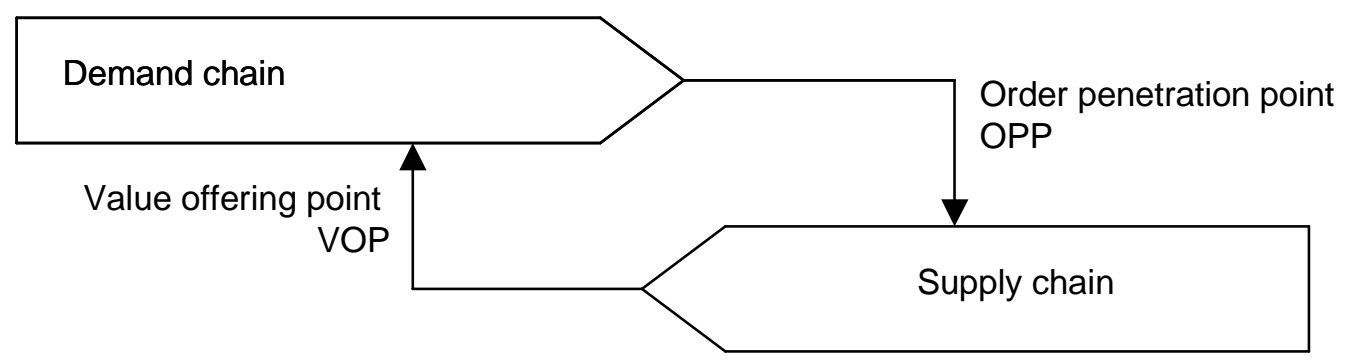

Figure 1: OPP and VOP linking supply and demand.

OPP theory relates closely to the postponement theory, which deals with delaying operations until customer demand is received (Bowersox and Closs, 1996). Van Hoek (2001) defines postponement as a concept in which some activities are not performed until customer orders are received. He points out that postponement is useful in supply chains where customised solutions are needed, product lifecycles are short, or demand fluctuations are large. According to Sharman (1984), the OPP is the last point at which inventory is held.

The value offering point (VOP) is the point in the customer's demand chain at which a supplier offers his solution to the customer (Holmström et al., 1999; Hoover et al., 2001). Beyond the VOP the customer operations rely on the suppliers' offer. Three basic types of alternative locations of VOP can be identified (see Figure 2). The first type is offer-to-purchasing, which can be described as a traditional arm's length relationship. The supplier operates with customer orders and endeavours to fulfil the need according to the required timetable. If a supplier takes responsibility for the customer's inventory 
management, for example in a vendor-managed inventory (VMI) relationship, the VOP location is in customer's inventory management (offer to inventory management). A step further is a relationship in which the supplier adjusts its value offering to the customer's planning process (offer to planning). Here the supplier takes part in, or even takes ownership of, the customer's planning process. The supplier is able to offer more know-how and better service and, therefore, value to the customer (Holmström, 1999; Collin, 2002).
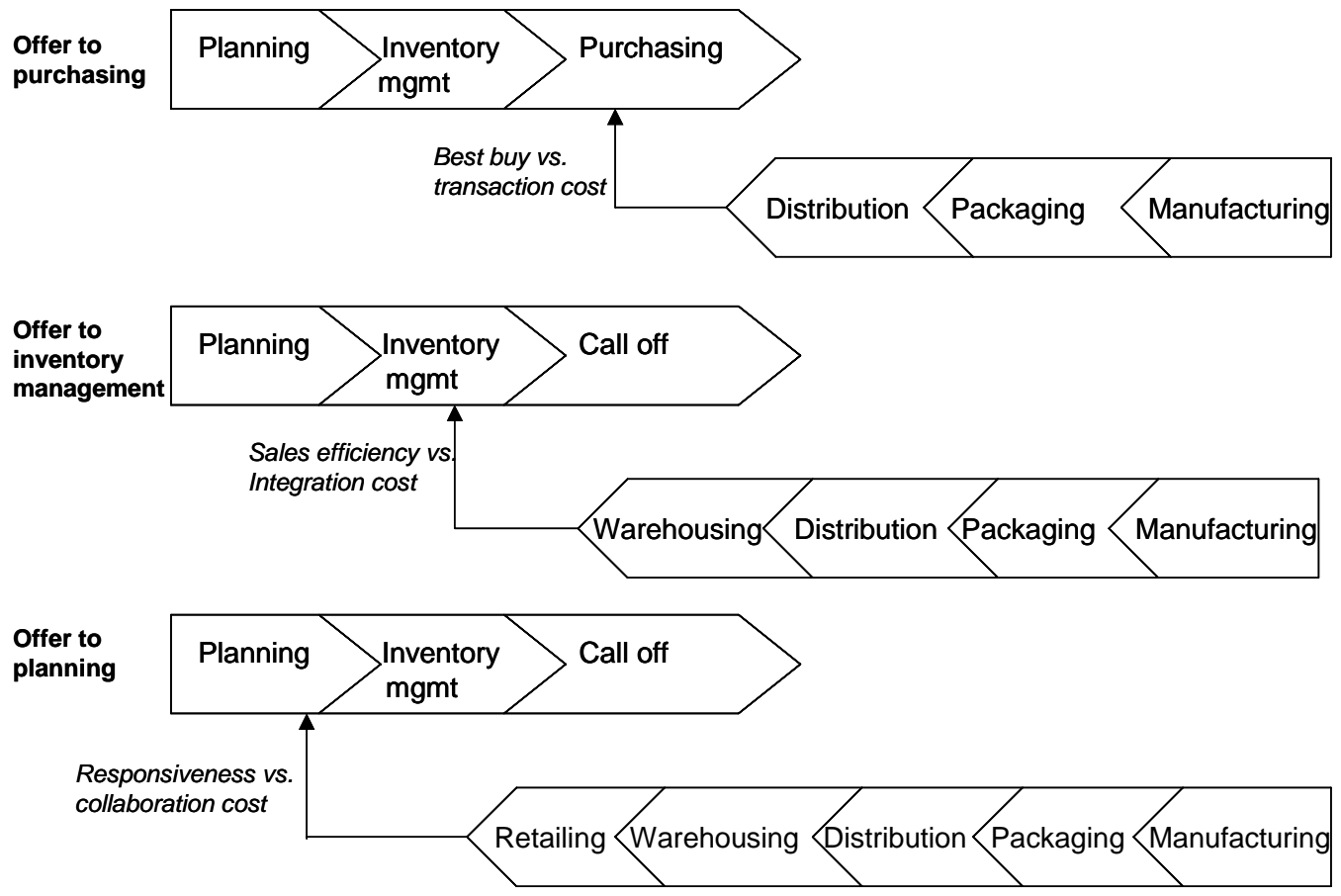

Figure 2: Location of VOP in different supplier - customer relationships

When moving the VOP, the supplier deals with the amount of value it offers the customer, and, accordingly, the degree of uncertainty it has to deal with. If a supplier moves the VOP upstream in the customer demand chain, to the right in Figure 2, the supplier potentially benefits by gaining better demand information and time. The supplier can synchronise its own operations in line with the pace of change at the customer end. The supplier has the incentive and opportunity to innovate and develop the relationship further in order to continue the relationship (Hoover et al., 2001).

The solution to avoid difficult trade-offs is working on the VOP and OPP simultaneously (Hoover et al. 1997). Moving the VOP often enables the supplier to move its order penetration point (OPP) and in this way increase its operational efficiency. For example, when the VOP is moved from purchasing to inventory management, the supplier gets access to demand data. This gives the supplier more time to fulfill demand and enables the OPP to be moved from the finished goods inventory of the manufacturer to, for instance, packaging without trading off between customer services and packaging capacity utilisation.

\section{Time benefit method for measuring improvement potential}

The goal of moving the VOP and OPP location is to choose the value that the supplier offers to customer. However, quantifying the impacts of change is required. The time benefit method offers a way to identify the potential benefits using time as a measure (Kaipia et al., 2002). Time benefit measures the potential benefit of incremental visibility in a supply chain. By using this method the advantage of closer collaboration between companies can be done by quantifying the advantage gained by the supplier from a more open information exchange in the supply chain. 
The time benefit method compares two potential collaboration modes, for example, using orders and open information exchange. Using this method, the evaluation of benefits from collaboration in the supply chain can be done beforehand on stock-keeping unit (SKU) level.

The time benefit method takes the following steps (for details see Kaipia et al. 2002)

1. Describe the existing mode of replenishment process - the base case - and one alternative mode. For example the base case is operating based on purchase orders and the alternative is operating based on VMI.

2. Collect demand data for the alternatives to be examined. For example the input for the base case is the purchase orders placed by the customer on the supplier and for the VMI, the alternative, the consumption by the customer or the sales to the customer's customer. The time period, which is examined, needs to be long enough for quantifying the delays between these two demand flows for all products in the product range.

3. Calculate the following for each item in the product range, and for both the base case and the alternative solution:

- Mean absolute deviation of demand (MAD). In our example in the non-VMI situation (base case) MAD is calculated from the order data from the customer to the supplier. In the VMI situation (alternative mode) MAD is calculated from the consumption data of the customer.

- Reorder point (ROP). The supplier's and the customer's safety stock and reorder point are defined

- Response time (RT), which is the time until due date, the time the the supplier has available for fulfilling the demand. In our example in the non-VMI situation response time is the same as the delivery time (RT1). In a VMI situation response time is the time between the inventory count and the moment supplier has to replenish to avoid a stock-out situation (RT2).

4. Calculate for each item in the product range the following:

- Time benefit, which is the difference between response times (RT2-RT1). In our example, estimating the potential increase in the response time for the VMI solution, the supplier's inventory before the shift to VMI is also needed as an input. The benefit derives from the fact, that in the VMI situation this buffer is not needed because the only relevant service level is to the customer's customer.

- Reordering amplification, which describes the strength of the bullwhip effect. First, variation of demand is calculated from the order data from the customer to supplier (MAD1), and from the consumption of the customer (MAD2). Reordering amplification is the relation of these two variations (MAD1 / MAD2). If the reordering amplification is 2, it means that on average the item is sold on to the customer twice as frequently as it is purchased.

5. Graph for each product item in the product range the time benefit and reordering amplification of demand.

In this paper these steps are carried out on the SKU level in the two cases.

\section{Methodology}

Previous papers dealing with the value offering theory (Holmström et al., 1999; Hoover et al., 2001) have focused on developing the theory and illustrating conceptually how more time can be gained for the supplier through changing the supplier's value offering. However, empirical verification is lacking. In addition, measuring the impact of moving the value offering point is a significant issue when attempting to substantiate the theory. The objective of this paper is to test the time benefit method by analysing the VOP moves in two supply chain settings. The testing has been completed through two industrial cases from different levels of the same grocery supply chain.

The objective of the research was to explore how value offering theory and TBM can be used in conjunction with the development of collaboration practices between the parties involved in the supply chain. The research problems investigated were:

1. How can value offering theory and time benefit method be used in practice to develop supply chain operations?

2. Is there a difference between employing the tools in upstream or downstream supply chain operations? 
These research questions were approached through two cases. Modelling the VOP is a managerial tool, which helps in systematically analysing a supplier-customer relationship and in choosing the right collaboration mode. Implementing the change requires changing the processes between supply chain parties. In the cases we are, first, analysing the information flows with time benefit tool. Second, we are considering the current locations of OPP and VOP and relocating them. The actual changes in the cases are either decided based on the analyses or further support for the change is sought through them. The role of the analyses is to point out if the performance of the supply chain can be improved by changing the information exchange and introducing the VMI operations model. Through the cases we are testing the suitability of the two methods in real-life supply chains.

The impacts of the implemented changes are measured using inventory levels and estimating other quantitative or qualitative benefits. Total monetary value of the changes is not considered.

The first case was from the manufacturer-retailer interface, and illustrates moving the VOP from purchasing first to inventory management and then further to planning. The case is based on longterm co-operation between a packaged consumer goods manufacturer and its distributor in a neighbouring country. The methods used were interviewing key persons and moving the VOP and analysing the impacts of the move with time benefit method. The time benefit method was used to reveal the hidden, unused time potentials on the individual product level (i.e. stock-keeping unit). The data used in the time benefit analysis concerned orders and replenishments, which were collected from the case company's information systems from two echelons of the case supply chain.

The second case describes the interface between a manufacturer and its suppliers. For a responsive grocery supply chain, collaboration also needs to be extended to material suppliers. A critical constraint in the consumer goods industry is the long lead times of packaging materials. In the second case, the interface between one packaging material supplier, one raw material supplier, and a manufacturer is analysed using the value offering theory and time benefit method. First, key persons responsible for purchasing, inventories and customer relationships were interviewed. Then the location of VOP was considered and time benefit was calculated. The data for the time benefit analysis were gained from the manufacturer's ERP system.

\section{Results}

In the first case we show how a company changes its value offering, VOP, from purchasing first to inventory management and then to planning in the customer's demand chain and how time benefit is used in the change process. The value offering theory and time benefit method are used together and the usefulness of using them simultaneously is explored in practice.

\section{Case 1: Moving the VOP in the manufacturer-retailer interface}

The example concerns the operations between a Finnish grocery manufacturer and its subsidiary company in a neighbouring country. The subsidiary is responsible for marketing, sales and logistics of the manufacturer's products in its local market. Before the development efforts were started the subsidiary generated orders for the manufacturer once a week based on a sales forecast created by the product managers of the subsidiary.

The subsidiary received replenishment from the manufacturer once a week. In the process there were numerous delays and information discrepancies. The first delay was in the customer demand chain, where the sales department was not systematically monitoring customer needs. Secondly, the purchasing manager who was responsible for forecasting did not always know in time about sales department plans for campaigns. The third issue concerned the inventory levels; they were not systematically monitored when replenishment quantities were decided. Fourth, when communicating demand to the manufacturer, only orders and forecasts frozen for four weeks were used. No changes in forecasts according to actual inventory levels or demand changes were allowed within the fourweek set period.

The situation was intolerable. Inventory levels were very high and inventory turnover was far too slow. At the same time there were serious shortages, especially of store-ready display pallets needed in sales promotions. Furthermore, sales frequently had to discount batches of products because of 
imminent obsolescence. This cost, which the company calls its "best-before -cost", was very high, exceeding eight percent of sales. Replenishment quantities fluctuated as the sales-company tried to respond to shortages and problems of obsolescence. Customers were not satisfied with service levels or with product freshness. Altogether, there were serious problems in the total process, and the sales company sustained losses.

The VOP model was applied to describe this offer-to-purchase relationship between the factory and the sales company. Deliveries to the sales company and the actual production were based on purchase orders. There were forecasts generated for production needs, but due to lack of co-ordination inside the sales company the forecast information was of low quality and unreliable.

To improve the situation, two types of changes were considered and implemented. First, the replenishment process was renewed and vendor-managed inventory principles were employed. The second step was to improve the forecasting process.

Step 1: manufacturer focuses on service to the sales company

The effect of changing the VOP from purchasing to inventory management was quantified using the time benefit measure through the 5 -step procedure. The analysis contains 16 products, and the analysis is run from the demand data from the subsidiary to the customers and from the demand data from the subsidiary to the manufacturer. The results indicate that the supplier achieves a time benefit of between 9 and 24 working days (Figure 3). The time benefit depends on the demand amplification, which describes how rarely orders are placed compared to consumption. This result shows that the supplier's benefit depends on how rarely orders were placed before VMI. The measured time benefit is the additional response time the manufacturer has available if it is able to monitor the inventory and sales of the subsidiary, rather than waiting for the order. This time can also be described as unused flexibility in the present supply chain, which could be employed to profit the supply chain in terms of improved customer service or cost efficiency, or a mix of both.

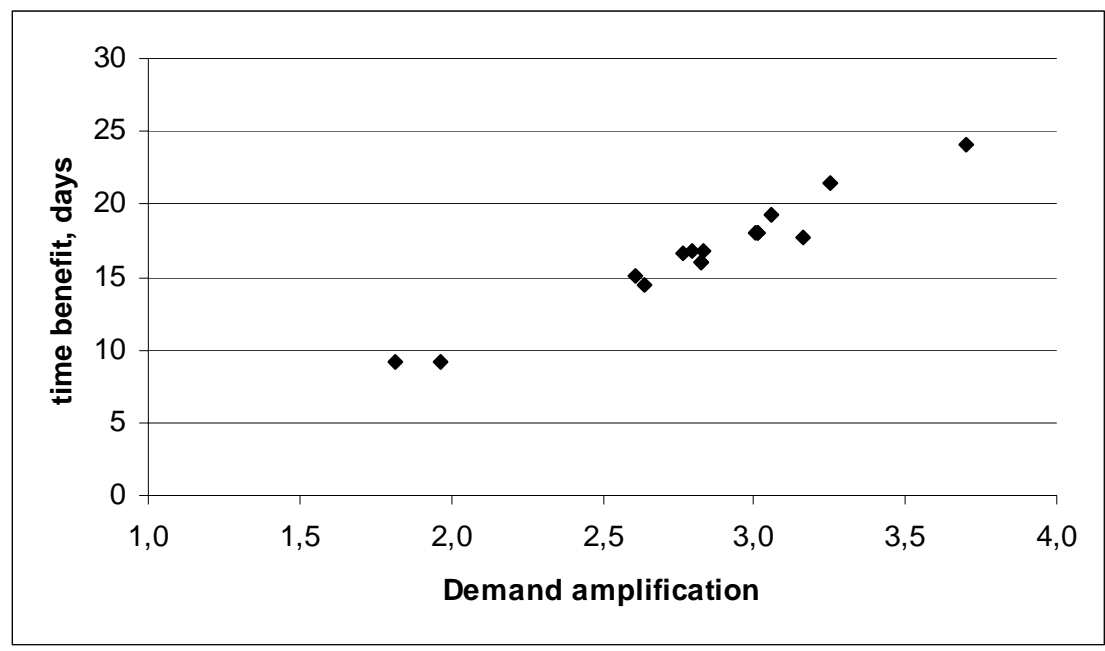

Figure 3. Time benefit for the supplier in Case 1. The points represent the supplier's potential time benefit per product before the operations were changed in the case supply chain.

The supplier realised it had the opportunity to improve its operational performance by moving its value offering point at the subsidiary to inventory management. The subsidiary's demand chain and the manufacturers supply chain and the moves of VOP and OPP are illustrated in Figure 4. The replenishment collaboration model was changed and a vendor-managed inventory system was adopted. The responsibility for replenishments was moved from the subsidiary to the manufacturer. A significant goal in this change was to reduce the inventory levels at the sales company without increasing inventories elsewhere in the pipeline or risking reduced service levels. The goal was achieved and, in addition, the amount of obsolete products was reduced significantly. 
The adopted replenishment process was simple: inventory level data were transferred to the manufacturer every morning. These data were compared to the forecast, which is updated every two weeks. The replenishment quantity is the difference between the forecast and inventory levels, calculated as full pallets. Physically replenishments took place the next day. In practice, the change requires speed and flexibility. One person is responsible for the VMI system at the manufacturer. While more frequent deliveries are required, the workload becomes more even and therefore easier to handle. Frequent freight connections between the two countries made the change possible.

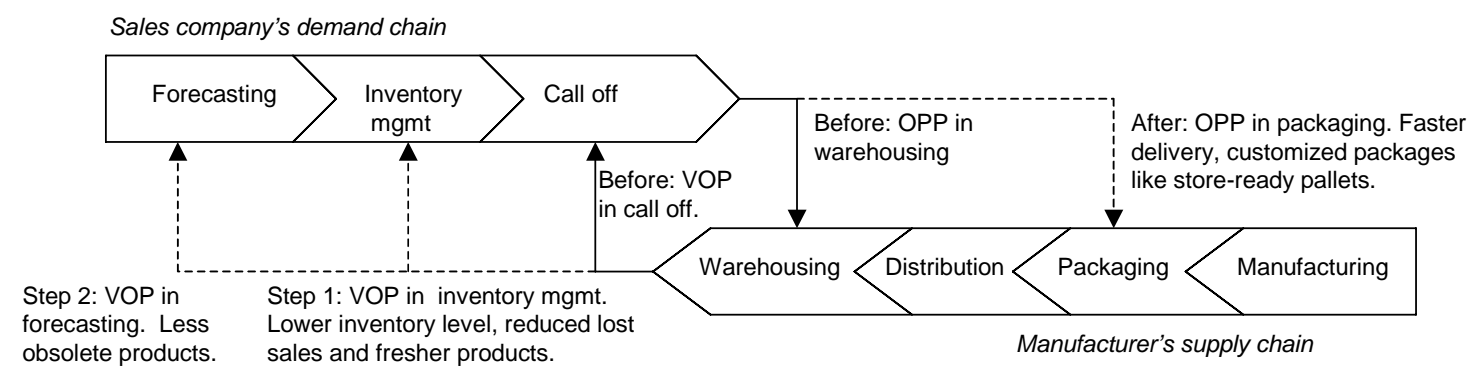

Figure 4. Shifting VOP and OPP in Case 1.

Step 2: Sales company focuses on demand forecasting

Another problem in the sales company were shortages caused by campaigns, promotions and seasonal product introductions that were not communicated in time. To solve this, better planning collaboration was needed between the factory and its subsidiary. The solution that could be achieved using the value offering theory would be to move the manufacturer's value offering to the planning process of the sales company. The manufacturer deepened its co-operation with the sales company and developed the delivery process so as to be able to respond better to promotional and assortment changes. The purpose was to give better sales information to the production, and improve the service level to the customer by offering products that customers needed and wanted, not what the sales company had.

The forecasting process in the sales company was completely changed. The sales department took the responsibility for forecasts and a forecasting manager was appointed. A 52-week rolling forecast was generated for every product. The forecast can be changed as much as needed, according to market changes, campaigns, or seasons up to the set forecast period. A much shorter fixed forecast period, of two weeks, was also introduced, which improved forecast accuracy. Based on the inventory situation, the set forecast period is needed in order to be able to determine when replenishment is to be dispatched to the sales company. Because the inventory situation is checked every day, the system is now more robust, with few forecast errors. More frequent replenishments are dispatched if demand is higher than forecast, and less replenishment takes place if demand is lower.

The change resulted in reduced inventory levels in the sales company (Figure 5). Total inventories in the whole chain were diminished throughout the product range despite the rise in the inventory level of some special products dedicated to this market. What is important in this product group is that the age distribution of the products in stock changed radically. The inventory of products that are in danger of becoming too old to be sold to customers, the black area in Figure 5, has almost disappeared. The obsolescence cost declined to one-fourth, from eight percent of sales to two percent, during the first months. These improvements ensure that consumers get much fresher products. Instead of discounting ageing product batches the sales department can concentrate more on customer needs, forecasting, campaigns and new product introductions so as to generate more sales and profit.

Seasonal changes in this product group are high. Christmas products are manufactured to stock during the summer and early autumn to be delivered to stores 10 to 3 weeks before Christmas. One Christmas peak in the inventory level can be seen in Figure 5 in Weeks 45-50. Based on replenishment collaboration, in the new operating model the seasonal peak is much lower - see Weeks 95-105 - and it is extended over a longer time period, which levels the logistical workload. 


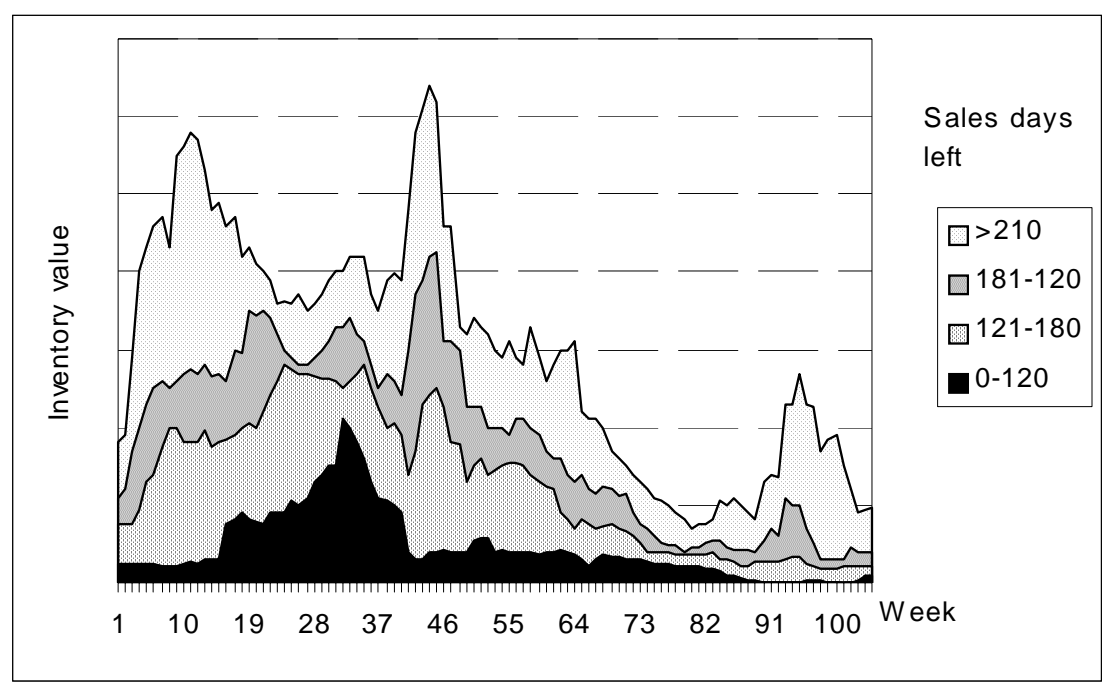

Figure 5. Inventory levels in monetary value in the sales company. VMI was implemented on Week 45. The different shades of grey represent the age distribution of products in stock in sales days. If product has less than 120 sales days left (black area) it is too old to be delivered to stores in a normal manner.

Case 2 - Developing the material supplier and manufacturer interface in the case grocery supply chain

In Case 2 the interface between the case manufacturer and two suppliers, one packing material supplier and one raw material supplier, was studied. The chosen packaging material vendor supplies approximately 170 different corrugated board items. The manufacturer placed orders to the supplier, who delivered the materials ordered with a delivery time of 20 working days. The manufacturer established weekly forecasts for the supplier's production planning needs. This way of working represented the actual procedure for most of the year in 2001. The chosen raw material supplier is one of the biggest raw material vendors for the manufacturer, and it sells the manufacturer several materials, with the most important ones being milk and milk powder.

Next, a mixed group of packaging materials and raw materials are analysed with time benefit calculations using the 5-step procedure. The situations compared are the order flow in the suppliermanufacturer interface as described above, and the replenishments based on a VMI solution. In total, eight packaging materials were randomly chosen for analysis from the supplier's material list, so that products from each volume category (products with highest volume belong to A-group, with medium volume to B-group and with lowest volume to C-group) were included at least twice in the calculations. The raw materials for time benefit calculations were chosen from different suppliers, who are potential or existing VMI -partners. The results can be seen in the chart (Figure 6) below. The letters at each plot describe the volume category of the materials.
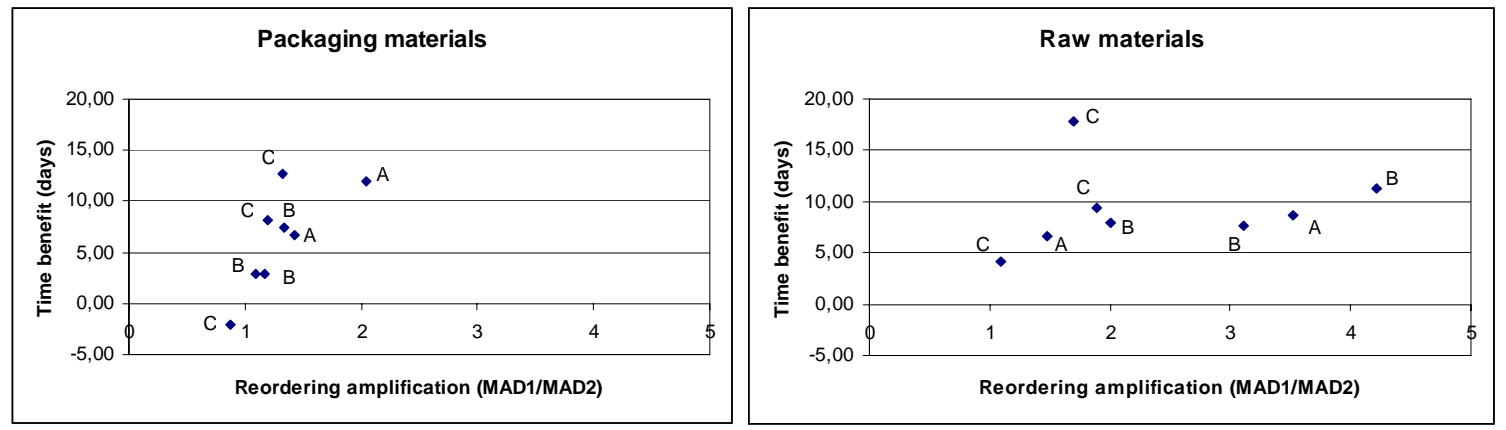

Figure 6. Time benefit for packaging materials and raw materials. 
The time benefit for materials from volume group A is from 6 to 12 days, and for B-materials 3-11 days. Time benefit for C-materials is more dispersed being 18 days at the maximum. One C-material has a negative time benefit value and the lowest demand amplification value, less than 1 . This indicates that the material was ordered more often than there is demand for it. The negative time benefit value indicates that there is no benefit for the supplier in running VMI-solution for this material.

When reviewing the reordering amplification figures, it can be seen that A-materials have more amplification than the C-materials. This phenomenon is explained by the differences in material demand being dependent upon the type of end product. In Figure 7 the orders and daily demand for four materials are plotted. The C-material orders are placed almost every time there is demand for the material and order lot size is two or three times that of production batch size. For the A-material, the ratio between order lot-size and demand is large.
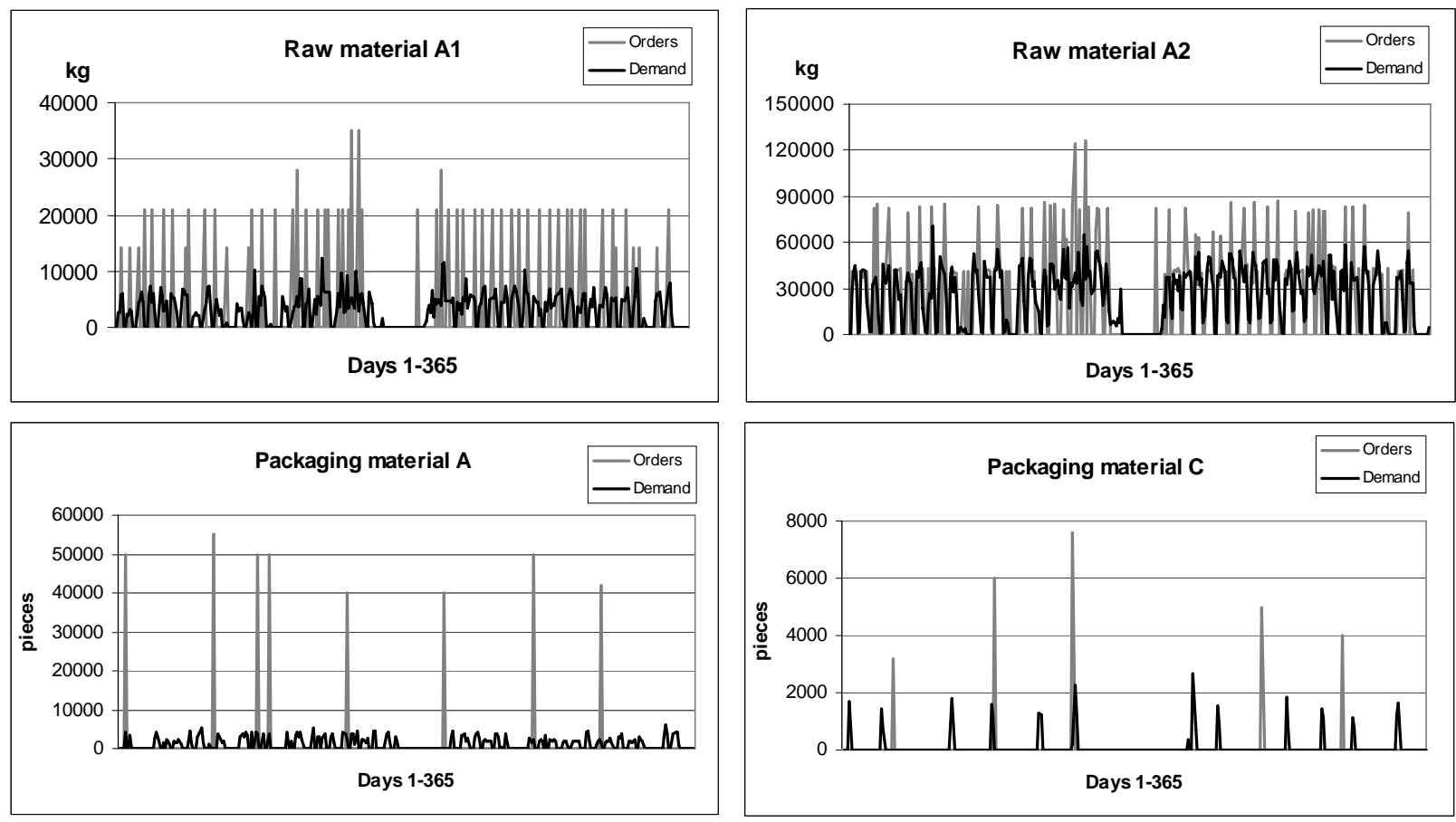

Figure 7. Orders and demand for two raw materials and two packaging materials.

The order amplification level is higher for raw materials than it is for packaging materials. Demand for the raw materials is more constant during the year than is the case for packaging materials. One type of raw material can be used in several products while packaging materials, for example, a printed box, are product-specific. Time benefit figures are higher for raw materials than for packaging materials, which indicates that one order covers demand for a longer time period. When ordering packaging materials, one order can cover the need of one separate production batch (Figure 7).

From the time benefit analyses (Figure 6) it can be seen that in both material groups exists development potential for the supplier if the responsibility for replenishment is re-positioned. The differences in product demand revealed that time benefit depends on the demand characteristics of the product, not on the product size. In the supplier-manufacturer interface one C-material order may cover a single production batch, and in this situation no time benefit will be gained for the supplier in VMI.

The vendor-managed inventory model was implemented for both case suppliers. The initiative came from the manufacturer, who wanted to reduce double handling work in the supply chain and lower administrative costs in purchasing and deliveries. The raw material supplier delivers large-volume materials that have relatively constant demand. However, greater attention was required by the buyers at the manufacturer in the traditional order-delivery process, both in managing their own 
production needs and when completing the paperwork. Reducing the unnecessary work brought about by generating orders was a compelling reason to implement VMI. The demand and supply chain structures and VOP-OPP movements are illustrated in Figure 8.

Manufacturer's demand chain

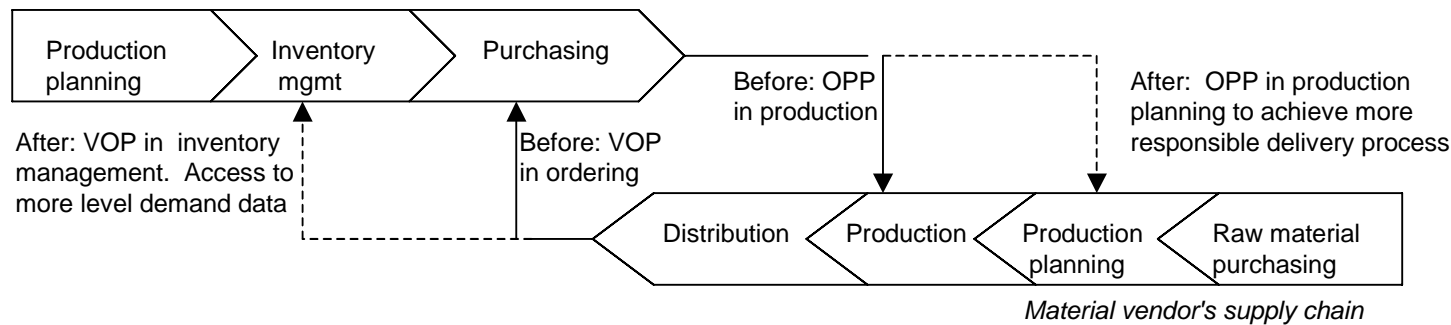

Figure 8. Movements of VOP and OPP in Case 2. If the material vendor is responsible for inventory management, the demand data can be used in delivery processes and in production planning.

The system has been able to fulfill the expectations for eliminating replicate work. The suppliers report that they can manage their own production and deliveries more easily and effectively, and their inventory management has improved.

However, there exists more potential in the relationship. The supplier companies do not use real-time demand data as input data in their own system. The production plans are made manually. Raw material suppliers use forecast figures provided by the manufacturer as a basis when planning their weekly and monthly production batches. Suppliers keep some work-in-process (WIP) inventories for urgent demand situations. The greatest benefits with the real-time data provided by the VMI -system occurs in surprising situations and when exact delivery amounts and time are needed.

When discussing the usability of real-time data we observe that upstream suppliers seem to suffer from lead-times for materials up to three months long. Even if they can see the changing demand on their computer screens, they are not able to react to this change because of long delivery lead times or a very inflexible production system. The upstream operations of this supply chain seem not to be as responsive as those downstream. Companies are forced to keep both work-in-process and finished goods inventories in order to protect themselves against uneven demand.

\section{Conclusions and further research}

Better supply chain development tools are needed if grocery supply chains are to be systematically developed to meet the demand to create effective operations. In this paper, we investigated how two development tools can be used in concert to reveal the development potential in two case supply chains. The second research question was if there is a difference in employing these tools in upstream and downstream operations.

The VOP analysis was used to explore which operations might be eliminated in the case supply chain. The challenge in using the VOP analysis has been in discovering which activities add value for the customer in different types of supply chains and which products should the activities concern. The time benefit method was used to identify the development potential in the supply chain. With this measurement the potential benefits on product level were made visible and those products that benefit most from demand visibility, as well as those products that do not benefit, were identified. Thus the parallel use of these tools support each other.

There emerged no difficulties in using the tools in different parts of the supply chain and different demand characteristics can be analysed by the use of the tools. An interesting result surfaced regarding the impact of demand characteristics on time benefit. When the first applications of time benefit and the results from the manufacturer-retailer interface are compared to the results of this study, it is evident that the time benefit in the grocery supply chain is different in the suppliermanufacturer interface than in the manufacturer-retailer interface. The biggest benefit from sharing demand information has been in a situation with constant demand, as this enables the value offering to be changed to a replenishment type of service. However, in the case demand chain, demand for 
materials and packaging is not level in the manufacturing operation due to batching and scheduling. The VOP-TBM analysis revealed that in the second case the full potential of VMI has not yet been realised in the supplier-manufacturer interface.

This paper contributes to value offering theory by presenting an example how it can be used in analysing real-life supply chains. There have been few empirical studies using the VOP tool. Furthermore, this is the first time when VOP analysis is completed with time benefit method. The power of the TBM tool can be seen in case 2, where different types of products were treated. The tool was used to estimate the value of VMI operations model and it could identify which products benefit most. In analyses different demand features could be handled and explained. However, TBM analyses treat only the benefits of replenishment collaboration, and the VOP model is needed to identify further development actions and collaboration forms as it can be used to reveal development actions beyond the area TBM is treating.

There have emerged three interesting areas for further research. The two cases of this paper are from grocery supply chains. Especially in case 1 attention is paid to the obsolescence problem of groceries; a single SKUs life cycle is predetermined by best-before dates and product freshness is extremely important for the product quality. However, inventory management and shortened product life cycles are an issue in other industries, for example in electronics and fashion industries. The use of the VOP and time benefit method in other industries and environments form one area of further research. The second issue is how the VMI operations mode is implemented in supply chains and which benefits have companies realised in VMI. This research would investigate how companies actually benefit from the calculated time benefit, revealed in the TBM analyses, in their processes. Last, upstream operations in general, and especially package material supply, seem to be an interesting further research issue. 


\section{References:}

Bowersox, D., and Closs, D., 1996 Logistics Management - The Integrated Supply Chain Process (Singapore: McGraw-Hill).

Christopher, M., 1998 Logistics and Supply Chain Management - Strategies for Reducing Costs and Improving Service (London: Pitman Publishing).

Collin, J., 2002 Selecting the Right Supply Chain for a Customer in Project Business Doctoral Thesis, Helsinki University of Technology.

Hellström, M., 2003 Requirements for Co-Managed Inventory in the Supplier-Manufacturer Interface, Master's Thesis, Helsinki University of Technology.

Hoekstra, S., and Romme, J., (eds) 1992 Integrated Logistics Structures: Developing Customer Oriented Goods Flow (London: McGraw-Hill).

Holmström, J., Hoover, W.E., Jr., Eloranta, E., and Vasara, A., 1999, Using Value Reengineering to Implement Breakthrough Solutions for Customers, International Journal of Logistics Management, Vol. 10, No. 2, pp. 1-12.

Hoover, W., E., Eloranta, E., Holmström, J., and Huttunen, K., 2001 Managing the Demand-Supply Chain - Value Innovations for Customer Satisfaction, (New York: John Wiley \& Sons, Inc.).

Kaipia, R. Holmström, J., and Tanskanen, K., 2002, VMI: What are you losing if you let your customer place orders? Production Planning \& Control, Vol. 13, No 1, pp. 17-25.

Lovelle, J., 2001 Mapping the value stream, IIE Solutions, Vol. 33, Iss. 2, pg. 26, 7 pgs.

Olhager, J., 1994 On the positioning of the customer order decoupling point, Proceedings from the 1994 Pacific Conference on Manufacturing, Jakarta, December 1994, pp. 1093-1100.

Sharman, G., 1984 The Rediscovery of Logistics Harvard Business Review, September-October, pp 71-79.

Van Hoek, R.I., 2001 The Rediscovery of Postponement - A Literature Review and Directions for Research Journal of Operations Management, Vol. 19, pp. 161-184.

Vollman, T., Berry, W., and Whybark, C., 1997 Manufacturing Planning and Control Systems (New York: McGraw-Hill).

Wood N., 2004 Learning to see: How does your supply chain function? Management Services, Vol. 48, Iss. 4, p. 16-19. 